\title{
The common personal behavior and preventive measures among 42 uninfected travelers from the Hubei province, China during COVID-19 outbreak: A cross-sectional survey in Macao SAR, China
}

\author{
Chon Fu Lio ${ }^{\text {Equal first author, } 1}$, Hou Hon Cheong ${ }^{\text {Equal first author, } 1}$, Chin Ion Lei ${ }^{\text {Corresp., } 2}$, Iek Long Lo ${ }^{3}$, Lan Yao ${ }^{4}$, Chong Lam ${ }^{5}$, \\ Iek Hou Leong ${ }^{5}$ \\ 1 Macao Academy of Medicine, Health Bureau, Macao SAR, China \\ Department of Medicine, Centro Hospitalar Conde de São Januário, Health Bureau, Macao SAR, China \\ 3 Department of Respiratory Medicine, Centro Hospitalar Conde de São Januário, Health Bureau, Macao SAR, China \\ 4 Health Bureau, Macao SAR, China \\ 5 Center for Disease Control and Prevention, Health Bureau, Macao SAR, China \\ Corresponding Author: Chin Ion Lei \\ Email address: cilei@ssm.gov.mo
}

Background. The novel coronavirus diseases 2019 (COVID-19) caused over 1.7 million confirmed cases and cumulative mortality up to over 110,000 deaths worldwide as of April 14, 2020. 57 Macao citizens were obligated to stay in Hubei province, China, where the highest COVID-19 prevalence was noted in the country and a "lockdown" policy was implemented for outbreak control for more than one month. They were escorted from Wuhan City to Macao via a chartered airplane organized by Macao SAR government and received quarantine for 14 days with none of the individual being diagnosed with COVID-19 by serial RNA tests from the nasopharyngeal specimens and sera antibodies. It was crucial to identify common characteristics among these 57 uninfected individuals.

Methods. A questionnaire survey was conducted to extract information such as behavior, change of habits and preventive measures.

Results. A total of 42 effective questionnaires were analyzed after exclusion of 14 infants and children with age under fifteen as ineligible for the survey and missing of one questionnaire, with a response rate of $97.7 \%$ (42 out of 43 ). The proportion of female composed more than $70 \%$ of this group of returners.

The main reason for visit Hubei in $88.1 \%$ of respondents is to visit relatives. Over $88 \%$ of respondents did not participate in high-risk activities due to mobility restriction. All (100\%) denied contact with suspected or confirmed COVID-19 cases. Comparison of personal hygiene habits before and during disease outbreak showed a significant increase in practice including wearing a mask when outdoor $(16.7 \%$ and $95.2 \%$, $\mathrm{P}<0.001)$ and often wash hands with soap or liquid soap $(85.7 \%$ and $100 \%, \mathrm{P}=0.031)$. 
1 The common personal behavior and preventive measures among 42 uninfected travelers from the

2 Hubei province, China during COVID-19 outbreak: a cross-sectional survey in Macao SAR, China 3

4 Chon Fu Lio ${ }^{1 \pi}$, Hou Hon Cheong ${ }^{2 \pi}$, Chin Ion Lei ${ }^{3 *}$, Iek Long $\mathrm{Lo}^{4}$, Lan Yao ${ }^{5}$, Chong Lam ${ }^{6}$, Iek 5 Hou Leong $^{7}$

7 1. Macao Academy of Medicine, Health Bureau, Macao SAR, China

8 2. Macao Academy of Medicine, Health Bureau, Macao SAR, China

9 3. Department of Medicine, Centro Hospitalar Conde de São Januário, Health Bureau, Macao 10 SAR, China

11 4. Department of Respiratory Medicine, Centro Hospitalar Conde de São Januário, Health

12 Bureau, Macao SAR, China

13 5. Health Bureau, Macao SAR, China

14 6. Center for Disease Control and Prevention, Health Bureau, Macao SAR, China

15 7. Center for Disease Control and Prevention, Health Bureau, Macao SAR, China 16

17 T: These authors contributed equally to this work

18

19

$20 *$ Corresponding Author:

21 Dr Chin Ion Lei

22 Chief of service

23 Department of Medicine

24 Centro Hospitalar Conde de São Januário

25 Health Bureau, Macao SAR, China

26 Email address: cilei@ssm.gov.mo 


\section{Abstract}

28 Background. The novel coronavirus diseases 2019 (COVID-19) caused over 1.7 million confirmed cases and cumulative mortality up to over 110,000 deaths worldwide as of April 14, 2020. 57 Macao citizens were obligated to stay in Hubei province, China, where the highest COVID-19 prevalence was noted in the country and a "lockdown" policy was implemented for outbreak control for more than one month. They were escorted from Wuhan City to Macao via a chartered airplane organized by Macao SAR government and received quarantine for 14 days with none of the individual being diagnosed with COVID-19 by serial RNA tests from the nasopharyngeal specimens and sera antibodies. It was crucial to identify common characteristics among these 57 uninfected individuals.

Methods. A questionnaire survey was conducted to extract information such as behavior, change of habits and preventive measures.

Results. A total of 42 effective questionnaires were analyzed after exclusion of 14 infants and children with age under fifteen as ineligible for the survey and missing of one questionnaire, with a response rate of $97.7 \%$ (42 out of 43 ). The proportion of female composed more than $70 \%$ of this group of returners. The main reason for visit Hubei in $88.1 \%$ of respondents is to visit relatives. Over $88 \%$ of respondents did not participate in high-risk activities due to mobility restriction. All (100\%) denied contact with suspected or confirmed COVID-19 cases. Comparison of personal hygiene habits before and during disease outbreak showed a significant increase in practice including wearing a mask when outdoor $(16.7 \%$ and $95.2 \%, \mathrm{P}<0.001)$ and often wash hands with soap or liquid soap ( $85.7 \%$ and $100 \%, \mathrm{P}=0.031)$. 


\section{Introduction}

49 The novel coronavirus disease 2019 (COVID-19) caused by the severe acute respiratory

50 syndrome coronavirus 2 (SARS-CoV-2) caused over 1.7 million confirmed cases and cumulative

51 mortality up to over 110,000 deaths worldwide as of April 14, 2020(WHO 2020b), provided with

52 its early transmission dynamic of human-to-human transmission among close contacts.(Li et al.,

53 2020) It is estimated in a model that COVID-19 would have resulted in 7.0 billion infections and

5440 million deaths globally in 2020 in the absence of any intervention.(Walker et al., 2020)

55 Wuhan City, the capital of Hubei province in China, became the first outbreak center of COVID-

5619 since December 2019.(Phelan, Katz \&Gostin 2020) During Chinese New Year Holidays,

57 Chinese people have the traditional habit of travel to hometown for a family reunion and

58 gathering to celebrate the beginning of a Lunar new year. Hence, many people including groups

59 of Macao citizens were obligated to stay in Hubei province after the announcement of

60 "lockdown"/sanitary cordons by the local government on 23 January 2020, i.e. 2 days before

61 Chinese New Year. It was until 7th March 2020, Macao SAR government escorted a special

62 team to Wuhan, China, to pick up 57 Macao citizens from 31 families, who stayed in 10 different

63 cities in Hubei province.(Portal 2020b) COVID-19 were ruled out in all of them afterwards.

64 A cross-sectional survey was conducted to have in-depth questionnaire interview of these people

65 who were all uninfected by SARS-CoV-2 in a high-risk area, Hubei province, China. This study

66 aims to identify the common grounds and personal behavior leading to a zero-infection rate

67 among participants that might provide crucial hints on global COVID-19 pandemic control.

Materials \& Methods

70 Participants, designs and settings

71 A citizen who presented with body temperature equal to or greater than 37.5 degree Celsius in

72 Hubei province was not allowed for boarding. After arrival to Macao, all 57 citizens were sent to

73 public health clinical center for a 14-day quarantine. A total of three serial nasopharyngeal swabs

74 were obtained on day 2, day 7 and day 13 for viral RNA detection by real-time RT-PCR

75 techniques, which were all negative (100\%).(Portal 2020a) Sera antibodies of SAR-CoV-2 were

76 tested with all negative results $(100 \%)$ on day 14 before citizens released from quarantine. All

77 citizens did not complain any symptoms during quarantine period. A questionnaire was designed

78 to obtain demographic information, activity in Hubei province, contact history, personal health 
79 behaviors such as habit of handwashing, mask usage and home cleaning. Participants aged 15 or 80 over were eligible for this study. The questionnaire survey was delivered to the isolation ward 81 and was implemented by self-administration. The written consents were collected as digital 82 format.

83 Infants and children with age under fifteen were considered ineligible for this survey. This study 84 was approved by the Hospital Medical Ethical Committee of Centro Hospitalar Conde de São 85 Januário, Macao SAR, China.

$87 \quad$ Statistical method

88 Descriptive statistic was used to summarize demographic information, high-risk activities and 89 common preventive measures via standard parameter such as percentage, mean and median.

90 Then we compared behavior changes before and during COVID-19 outbreak using Wilcoxon 91 signed rank test in continuous variables or McNemar test in dichotomized variables. The 92 statistical significance level was determined at $\alpha=0.05$. The statistical analysis was conducted 93 using R (version 3.5.2, R Development Core Team 2018).

\section{Results}

96 A total of 42 effective questionnaires were analyzed in final after exclusion of 14 infants and 97 children with age less than 15 years old and missing of one questionnaire (response rate: 97.7\%). 98 The demographic information was summarized in Table 1 . The majority of the participants aged 99 between 20-44 years old (52.4\%) and had received secondary education or above (97.6\%). The 100 proportion of female composed more than $70 \%$ of this group of returners. The most common 101 comorbid diseases were hypertension (7.1\%), followed by diabetes mellitus (4.8\%) and hepatitis

$102(4.8 \%)$. More than half of the respondents were non-smokers $(61.9 \%)$. The main reason for visit 103 Hubei is to visit relatives (88.1\%). More than eighty-five percent of participants thought the most 104 important reason of not getting COVID-19 was to keep distance ("stay away") from the crowd 105 and decrease cluster or gathering incidence, followed by good personal protective measures 106 (73.8\%).

107 Mobility and participation of high-risk activities were restricted for these participants in Hubei 108 province according to the emergency response policy and these were specified by these 109 respondents (Table 2): $97.6 \%$ of them did not visit crowded places; $90.5 \%$ of them did not use 
110 any public transportation; $90.5 \%$ did not go to any supermarket. About three-quarters of 111 respondents received daily supply at home via unified delivery. None of them visited or traveled 112 to other provinces or cities $(0 \%)$. All the participants $(100 \%)$ denied any contact with suspected 113 or confirmed COVID-19 patients while $4.8 \%$ of the participants stated there was confirmed 114 COVID-19 cases in their local community.

115 A further survey of comparison of personal preventive measures before and during disease 116 outbreak showed increased alert and practice of personal protection and hygiene during the 117 spread (Table 3), such as wearing a mask when outdoor (16.7\% and 95.2\%, $\mathrm{P}<0.001)$, wearing a 118 mask every time when contact or talk with people $(10 \%$ and $95 \%, \mathrm{P}<0.001)$, often wash hands 119 with soap/liquid soap ( $85.7 \%$ and $100 \%, \mathrm{P}=0.031)$, use of alcohol-based hand sanitizers or 120 disinfected wipes as substitute if handwashing facility not available $(71.4 \%$ and $95.2 \%$, $121 \mathrm{P}=0.006)$, cleaning clothes and personal belongings immediately once get back home (35.7\% and $12278.6 \%, \mathrm{P}<0.001)$, cleaning mobile phone regularly (43.9\% and 65.9\%, $\mathrm{P}=.012)$. Only $11.9 \%$ of 123 respondents attend meal gatherings regularly during the spread compared to $59.5 \%$ before $124(\mathrm{P}<0.001)$. The increase in personal measures is significant and may possibly reflect the 125 effectiveness of public health interventions.

\section{Discussion}

128 The aims of this research was to investigate the reasons that contributed to the negativeness of 129 COVID-19 in this high-risk population in Hubei province. On the one hand, good physical health 130 could be one factor, as the majority of participants were below the age of 45 (61.9\%), nonsmokers (61\%) and 85.7\% had no underlying chronic diseases. However, further studies are needed to determine the exact effect of physical health on the risk of COVID-19 infection. On the other hand, it was also important to stop the transmission chain via political measures or personal health behaviors.

135 On 23 January 2020 (2 days before the Chinese New Year), the China government imposed a "lockdown" in Wuhan and other cities in Hubei to quarantine this center, which is commonly referred to as the "Wuhan lockdown".(Health-Commission. 2020) All public transport, including

138 buses, railways, flights, and ferry services were suspended with all stations and airports closed. The residents of Wuhan were not allowed to leave the city without permission which was unprecedented in public health history. Besides, measures on social aspects including the ban on 
141 massive gatherings such as concerts or competitions, close of entertainment venues and public

142 facilities, schools closure and mandatory orders of wearing masks in public areas, were applied

143 to mitigate the outbreak by controlling the source of infection and block transmission routes.(Pan

144 et al., 2020) As a result, the respondents of our study reported the highly restricted mobility in

145 Wuhan, China. 97.6\% of them denied visiting crowded places which required high self-

146 discipline and other public measures to cooperate. To achieve this level of mobility restriction,

147 local authority organized a team of volunteers to facilitate the delivery of foods and other supply

148 to each home quarantine family(Chinanews.com. 2020), 76.2\% of participants received essential

149 materials via this method that decreased the chance of outdoor activity and interaction with

150 other. Nonetheless, $85 \%$ of respondents said that "staying away from crowds" was the major

151 reason to be not infected. Moreover, there were emerging evidence suggesting these "lockdown"

152 measures had certain roles on decreasing COVID-19 incidence.(Colbourn ; Gostin \&Wiley 2020;

153 Klompas et al., 2020; Phelan, Katz \&Gostin 2020; The Lancet Respiratory 2020) It was

154 estimated that the Wuhan travel ban delayed the epidemic progression by 3 to 5 days in mainland

155 China,(Chinazzi et al., 2020; Tian et al., 2020) while reducing case importations to other

156 countries by nearly $80 \%$ through mid-February(Chinazzi et al., 2020). Furthermore, the rates of

157 confirmed cases and the effective reproduction number $(\mathrm{Rt})$, i.e. the mean number of secondary

158 cases generated by a typical primary case at time t in a population, declined since January 24 ,

159 2020, and fell below 1.0 since February 6, 2020, in a recent investigation.(Pan et al., 2020)

160 Although intensive physical distancing and "lockdown" could help "flattening the curve" on

161 COVID-19 and preventing the sharp upward demand of health system capacities, the

162

consideration of social and economic effects of "lockdown" and knock-on effects on health such

163

as mental health and interpersonal violence is necessary.(Parmet \&Sinha 2020) Yet, our data

164

showed that over half of the participants (57.1\%) felt 'calm' during stay in Hubei province, which was somehow counterintuitive. We hypothesized that the provision of sufficient logistic support to the isolated families by local authorities and clear information delivery to the public during a "lockdown" will help to ease the stress and minimize subsequent psychological impact.(Brooks et al., 2020). Therefore, local governments should be advised to create a comprehensive strategy and to prudentially evaluate the following concerns including racisms, adequate explanations to the public about the rationale and upside, logistic power and resources, and cultural factors 
$172 \&$ Sinha 2020) The administration of "lockdown" could even lead to precarious situations that

173 could heighten transmission in some countries if corresponding supports are not tailor-made and

174 comprehensive based on their own economic and social conditions, such as workers may be

175 packed in state-run shelter during India "lockdown”.(Pulla 2020) Likewise, the announcement of

176 closing the gambling industry during the first half of February in Macau was accompanied with

177 foreseen policies of financial and resources supply could be one of the references of

178 administration of any kind of measures.(Portal. 2020)

179 Additionally, the significant behavior changes among participants before and during outbreak

180 consisted of more wearing a mask outdoor, wash hands more frequently, clean and disinfect

181 home more frequently, and less meal gatherings. Although the transmission of SARS-CoV-2 was

182 commonly believed via droplet and contact, no evidence of wearing a surgical mask alone by

183 healthy persons can prevent them from infection with respiratory viruses including COVID-19

184 currently while inappropriate use/disposal may even increase risk.(WHO 2020a) However, none

185 of the participants in our study agreed that it was less important to wash hands after wearing

186 masks, and all of them (100\%) believed that the incidence of accidental touching the face or nose

187 after wearing a mask would be reduced. The effectiveness of personal protective measures in

188 preventing pandemic influenza transmission by meta-analysis showed a significant protective

189 effect of hand hygiene but mixed results for mask use and thus wearing mask was suggested to

190 be applied alongside with hands hygiene.(Saunders-Hastings et al., 2017) Wearing mask might

191 also act as a "symbolism" on increasing individual awareness of good hygiene practice.(Klompas

192 et al., 2020) However, the universal mask-wearing scheme in public should be emphasized on

193 the concurrent hand hygiene practice and social distancing as a bundle, while the allocation and

194 availability of resources should be taken into account first to ensure adequate protection for

195 healthcare workers.(Emanuel et al., 2020).

196 There were some limitations in this study. The E.L.I.Z.A kits used for antibody detection were

197 qualitative and not able to provide titers information. Although the sample size of this questionnaire

198 was limited and recall bias was inevitable, its implication may indirectly reflect the effectiveness

199 of public health interventions in Wuhan, China, including sanitary cordon, traffic restriction,

200 social distancing, home confinement, centralized quarantine, and universal symptom survey.

201 Such interventions were aimed at preventing individuals from face-to-face interaction and

202 preventing asymptomatic COVID-19 patients from spreading the coronavirus within the 
203 community. The lack of infected citizens limits for further comparison of difference of measures 204 or behavior and further studies are warranted to determine the effectiveness of each preventive 205 measure on COVID-19 at the individual level. Moreover, some of the participants had stayed in 206 their relative home where the cleaning duty was not their responsibilities. Hence the question of 207 home cleaning might partially reflect the attitudes from their relatives/friends. 208

\section{Conclusions}

210 Our findings were in line with common preventive measures advised by the World Health 211 Organization. Good personal hygiene and adequate preventive measures such as less gathering, 212 frequent handwashing, in addition to wearing a mask outdoor, were common grounds among 42 213 uninfected participants during the stay in Hubei province under COVID-19 outbreak.

214 Furthermore, the success of the "lockdown" and self-quarantine policy in Hubei province could 215 contribute to the local authority's strong logistical provision and transparency of information 216 about the policy's rationale in order to maintain better mental health and thus increase 217 compliance and efficacy of preventive measures. 


\section{Acknowledgements}

219 We thank Dr. Tan Fong Cheong and Ms. Hong Lei Lou for their assistance in data collection and 220 coordination.

221

\section{References}

223

224

225

226

227

228

229

230

231

232

233

234

235

236

237

238

239

240

241

242

243

244

245

246

247

248

249

250

Brooks SK, Webster RK, Smith LE, Woodland L, Wessely S, Greenberg N, and Rubin GJ. 2020. The psychological impact of quarantine and how to reduce it: rapid review of the evidence. The Lancet 395:912-920. 10.1016/S0140-6736(20)30460-8

Chinanews.com. 2020. "Unified purchase of daily supplies by regular assessment in Wuhan community." Published online 15 February 2020. (accessed 16 April 2020). Available at http://www.chinanews.com/shipin/cns/2020/02-15/news848064.shtml.

Chinazzi M, Davis JT, Ajelli M, Gioannini C, Litvinova M, Merler S, Pastore y Piontti A, Mu K, Rossi L, Sun K, Viboud C, Xiong X, Yu H, Halloran ME, Longini IM, and Vespignani A. 2020. The effect of travel restrictions on the spread of the 2019 novel coronavirus (COVID-19) outbreak. Science:eaba9757. 10.1126/science.aba9757

Colbourn T. COVID-19: extending or relaxing distancing control measures. The Lancet Public Health. 10.1016/S2468-2667(20)30072-4

Emanuel EJ, Persad G, Upshur R, Thome B, Parker M, Glickman A, Zhang C, Boyle C, Smith M, and Phillips JP. 2020. Fair Allocation of Scarce Medical Resources in the Time of Covid-19. New England Journal of Medicine. 10.1056/NEJMsb2005114

Gostin LO, and Wiley LF. 2020. Governmental Public Health Powers During the COVID-19 Pandemic: Stay-at-home Orders, Business Closures, and Travel Restrictions. JAMA. 10.1001/jama.2020.5460

Health-Commission. WM. 2020. Control Strategies for Novel coronavirus infections in Wuhan City. Published online 2 February 2020. (accessed 14 April 2020) Available at http://wjw.wuhan.gov.cn/front/web/showDetail/2020020209339.

Klompas M, Morris CA, Sinclair J, Pearson M, and Shenoy ES. 2020. Universal Masking in Hospitals in the Covid-19 Era. New England Journal of Medicine. 10.1056/NEJMp2006372

Li Q, Guan X, Wu P, Wang X, Zhou L, Tong Y, Ren R, Leung KSM, Lau EHY, Wong JY, Xing X, Xiang N, Wu Y, Li C, Chen Q, Li D, Liu T, Zhao J, Liu M, Tu W, Chen C, Jin L, Yang R, Wang Q, Zhou S, Wang R, Liu H, Luo Y, Liu Y, Shao G, Li H, Tao Z, Yang Y, Deng Z, Liu B, Ma Z, Zhang Y, Shi G, Lam TTY, Wu JT, Gao GF, Cowling BJ, Yang B, Leung GM, and Feng Z. 2020. Early Transmission Dynamics in Wuhan, China, of Novel Coronavirus-Infected Pneumonia. New England Journal of Medicine 382:1199-1207. 10.1056/NEJMoa2001316 
251

252

253

254

255

256

257

258

259

260

261

262

263

264

265

266

267

268

269

270

271

272

273

274

275

276

277

278

279

280

281

282

283

Pan A, Liu L, Wang C, Guo H, Hao X, Wang Q, Huang J, He N, Yu H, Lin X, Wei S, and Wu T. 2020. Association of Public Health Interventions With the Epidemiology of the COVID-19 Outbreak in Wuhan, China. JAMA. 10.1001/jama.2020.6130

Parmet WE, and Sinha MS. 2020. Covid-19 - The Law and Limits of Quarantine. New England Journal of Medicine. 10.1056/NEJMp2004211

Phelan AL, Katz R, and Gostin LO. 2020. The Novel Coronavirus Originating in Wuhan, China: Challenges for Global Health Governance. JAMA. 10.1001/jama.2020.1097

Portal MSG. 2020a. 57 Macao residents return from Hubei released from quarantine. Published online 20 March 2020. (accessed 14 April 2020). Available at https://www.gov.mo/zh-hant/news/324201/.

Portal MSG. 2020b. 57 Macao residents return home safely from Hubei. Published online 8 March 2020. (accessed 7 April 2020) Available at https://www.gov.mo/en/news/123406/.

Portal. MSG. 2020. The Chief Executive of Macau SAR announced: Gambling industry will be suspended for half month and people should stay at home to avoid from COVID-19. Published online 4 February 2020. (accessed 16 April 2020). Available at https://www.gov.mo/zh-hant/news/316919/.

Pulla P. 2020. Covid-19: India imposes lockdown for 21 days and cases rise. BMJ 368:m1251. 10.1136/bmj.m1251

Saunders-Hastings P, Crispo JAG, Sikora L, and Krewski D. 2017. Effectiveness of personal protective measures in reducing pandemic influenza transmission: A systematic review and meta-analysis. Epidemics 20:1-20. https://doi.org/10.1016/j.epidem.2017.04.003

The Lancet Respiratory M. 2020. COVID-19: delay, mitigate, and communicate. The Lancet Respiratory Medicine 8:321. 10.1016/S2213-2600(20)30128-4

Tian H, Liu Y, Li Y, Wu C-H, Chen B, Kraemer MUG, Li B, Cai J, Xu B, Yang Q, Wang B, Yang P, Cui Y, Song Y, Zheng P, Wang Q, Bjornstad ON, Yang R, Grenfell BT, Pybus OG, and Dye C. 2020. An investigation of transmission control measures during the first 50 days of the COVID-19 epidemic in China. Science:eabb6105. 10.1126/science.abb6105

Walker P, Whittaker C, Watson O, Baguelin M, Ainslie K, Bhatia S, Bhatt S, Boonyasiri A, Boyd O, Cattarino L, Cucunuba Perez Z, Cuomo-Dannenburg G, Dighe A, Donnelly C, Dorigatti I, Van Elsland S, Fitzjohn R, Flaxman S, Fu H, Gaythorpe K, Geidelberg L, Grassly N, Green W, Hamlet A, Hauck K, Haw D, Hayes S, Hinsley W, Imai N, Jorgensen D, Knock E, Laydon D, Mishra S, Nedjati Gilani G, Okell L, Riley S, Thompson H, Unwin H, Verity R, Vollmer M, Walters C, Wang H, Wang Y, Winskill P, Xi X, Ferguson N, and Ghani A. 2020. The global impact of COVID-19 and strategies for mitigation and suppression. (accessed 14 April 2020). Imperial College COVID19 Response Team

Peer) reviewing PDF | (2020:04:47991:1:2:NEW 20 May 2020) 
284 WHO. 2020a. Advice on the use of masks in the context of COVID-19. Published online 8 March 2020.

285

286

287

288

289

290

291 (accessed 14 April 2020) Available at https://www.who.int/publications-detail/advice-on-the-useof-masks-in-the-community-during-home-care-and-in-healthcare-settings-in-the-context-of-thenovel-coronavirus-(2019-ncov)-outbreak.

WHO. 2020b. Coronavirus disease 2019 (COVID-19) Situation Report - 84. (accessed 14 April 2020). Available at https://www.who.int/docs/default-source/coronaviruse/situation-reports/20200413sitrep-84-covid-19.pdf?sfvrsn=44f511ab 2 . 


\section{Table 1 (on next page)}

Demographic information among the respondents returned from Hubei, China during COVID-19 outbreak in early 2020 


\begin{tabular}{|c|c|c|c|}
\hline & Total $(\mathrm{N}=42)$ & Male $(\mathrm{N}=11)$ & Female $(\mathrm{N}=31)$ \\
\hline Proportion & $100 \%$ & $26.2 \%$ & $73.8 \%$ \\
\hline Age (mean, SD) & $40.2,14.8$ & $42.9,16.8$ & $39.3,14.1$ \\
\hline $15-19$ & $4(9.5 \%)$ & $1(9.1 \%)$ & $3(9.7 \%)$ \\
\hline $20-44$ & $22(52.4 \%)$ & $4(36.4 \%)$ & $18(58.1 \%)$ \\
\hline $45-54$ & $10(23.8 \%)$ & $4(36.4 \%)$ & $6(19.4 \%)$ \\
\hline $55-64$ & $4(9.5 \%)$ & $1(9.1 \%)$ & $3(9.7 \%)$ \\
\hline 65 or above & $2(4.8 \%)$ & $1(9.1 \%)$ & $1(3.2 \%)$ \\
\hline \multicolumn{4}{|l|}{ Education level } \\
\hline Primary education or less & $1(2.4 \%)$ & $0(0 \%)$ & $1(3.6 \%)$ \\
\hline Secondary education & $18(42.9 \%)$ & $4(36.4 \%)$ & $14(50.9 \%)$ \\
\hline Bachelor's degree & $16(38.1 \%)$ & $4(36.4 \%)$ & $12(42.9 \%)$ \\
\hline Master's degree or above & $2(4.8 \%)$ & $1(9.1 \%)$ & $1(18.9 \%)$ \\
\hline Missing data & $5(11.9 \%)$ & $2(18.2 \%)$ & $3(9.7 \%)$ \\
\hline Presence of chronic disease(s) & $7(16.7 \%)$ & $2(18.2 \%)$ & $5(16.1 \%)$ \\
\hline Hypertension & $3(7.1 \%)$ & $1(9.1 \%)$ & $2(6.5 \%)$ \\
\hline Diabetes Mellitus & $2(4.8 \%)$ & $0(0 \%)$ & $2(6.5 \%)$ \\
\hline Hepatitis & $2(4.8 \%)$ & $0(0 \%)$ & $2(6.5 \%)$ \\
\hline Dyslipidemia & $1(2.4 \%)$ & $1(9.1 \%)$ & $0(0 \%)$ \\
\hline None & $36(85.7 \%)$ & $10(90.1 \%)$ & $26(83.9 \%)$ \\
\hline \multicolumn{4}{|l|}{ Tabagism } \\
\hline Current Smoker & $10(23.8 \%)$ & $4(36.4 \%)$ & $6(19.3 \%)$ \\
\hline Ex-smoker & $6(14.3 \%)$ & $2(18.2 \%)$ & $4(12.9 \%)$ \\
\hline Never & $26(61.9 \%)$ & $5(45.5 \%)$ & $21(67.7 \%)$ \\
\hline \multicolumn{4}{|l|}{ Reason for visit Hubei } \\
\hline Visit relatives & $37(88.1 \%)$ & $10(90.1 \%)$ & $27(87.1 \%)$ \\
\hline Business trip & $0(0 \%)$ & $0(0 \%)$ & $0(0 \%)$ \\
\hline Other reasons & $5(11.9 \%)$ & $1(9.1 \%)$ & $4(12.9 \%)$ \\
\hline \multicolumn{4}{|l|}{ Location of accommodation } \\
\hline City center & $14(33.3 \%)$ & $4(36.4 \%)$ & $10(32.2 \%)$ \\
\hline Countryside or town & $11(26.2 \%)$ & $3(27.3 \%)$ & $8(25.8 \%)$ \\
\hline Village & $17(40.5 \%)$ & $4(36.4 \%)$ & $13(41.9 \%)$ \\
\hline \multicolumn{4}{|c|}{ Number of people cohabit to share the bedroom } \\
\hline Alone & $14(33.3 \%)$ & $3(27.3 \%)$ & $11(35.5 \%)$ \\
\hline 2 people & $16(38.1 \%)$ & $3(27.3 \%)$ & $13(41.9 \%)$ \\
\hline
\end{tabular}




\begin{tabular}{|l|c|c|c|}
\hline 3 people & $8(19 \%)$ & $3(27.3 \%)$ & $5(16.1 \%)$ \\
\hline 4 people or above & $4(9.5 \%)$ & $2(18.2 \%)$ & $2(6.5 \%)$ \\
\hline
\end{tabular}

1 


\section{Table 2 (on next page)}

High-risk activities and daily supply conditions among respondents during COVID-19 outbreak in early 2020 in Hubei, China 


\begin{tabular}{|l|c|c|c|}
\hline & \multicolumn{3}{|c|}{ Participants replied "yes" } \\
\hline & $\begin{array}{c}\text { Total } \\
(\mathrm{N}=42)\end{array}$ & $\begin{array}{c}\text { Male } \\
(\mathrm{N}=11)\end{array}$ & $\begin{array}{c}\text { Female } \\
(\mathrm{N}=31)\end{array}$ \\
\hline Visit other cities in Hubei province (\%) & $0(0 \%)$ & $0(0 \%)$ & $0(0 \%)$ \\
\hline Visit other provinces (\%) & $0(0 \%)$ & $0(0 \%)$ & $0(0 \%)$ \\
\hline Go to hospital or clinic (\%) & $5(11.9 \%)$ & $2(18.2 \%)$ & $3(9.7 \%)$ \\
\hline $\begin{array}{l}\text { Contact with suspected/confirmed COVID-19 } \\
\text { patients (\%) }\end{array}$ & $0(0 \%)$ & $0(0 \%)$ & $0(0 \%)$ \\
\hline $\begin{array}{l}\text { Local community with confirmed COVID-19 cases } \\
\text { (\%) }\end{array}$ & $2(4.8 \%)$ & $2(18.2 \%)$ & $0(0 \%)$ \\
\hline Use of public transportation (\%) & $4(8.5 \%)$ & $2(18.2 \%)$ & $2(6.5 \%)$ \\
\hline Go to supermarket (\%) & $4(8.5 \%)$ & $2(18.2 \%)$ & $2(6.5 \%)$ \\
\hline Visit crowded places (\%) & $1(2.4 \%)$ & $1(9.1 \%)$ & $0(0 \%)$ \\
\hline Contact with live poultry (\%) & $2(4.8 \%)$ & $1(9.1 \%)$ & $1(3.2 \%)$ \\
\hline Eat game meats (\%) & $0(0 \%)$ & $0(0 \%)$ & $0(0 \%)$ \\
\hline Receive daily supply via the unified delivery (\%) & $32(76.2 \%)$ & $8(72.7 \%)$ & $24(77.4 \%)$ \\
\hline
\end{tabular}

1 


\section{Table 3(on next page)}

Comparison of personal preventive measures before and during the COVID-19 outbreak among non-infected respondents who traveled to Hubei, China during COVID-19 outbreak in 2020 


\begin{tabular}{|c|c|c|c|c|}
\hline & $\begin{array}{l}\text { Number of } \\
\text { missing data }\end{array}$ & $\begin{array}{l}\text { Before outbreak } \\
\text { (In Macau) }\end{array}$ & $\begin{array}{l}\text { During outbreak } \\
\text { (In Hubei) }\end{array}$ & $P$ value \\
\hline $\begin{array}{l}\text { Wear a mask when outdoor } \\
(\text { Yes, \%) }\end{array}$ & 0 & $7 / 42(16.7 \%)$ & $40 / 42(95.2 \%)$ & $<0.001 *$ \\
\hline \multicolumn{5}{|l|}{$\begin{array}{l}\text { Wear a mask when } \\
\text { contact/talk with people } \\
\text { (except those living } \\
\text { together) }\end{array}$} \\
\hline Every time (Yes, \%) & 2 & $4 / 40(10 \%)$ & $38 / 40(95 \%)$ & $<0.001^{*}$ \\
\hline Occasional (Yes, \%) & 2 & $4 / 40(10 \%)$ & $1 / 40(2.5 \%)$ & 0.375 \\
\hline No (Yes, \%) & 2 & $32 / 40(80 \%)$ & $1 / 40(2.5 \%)$ & $<0.001 *$ \\
\hline $\begin{array}{l}\text { Often wash your hands with } \\
\text { soap / liquid soap (Yes, \%) }\end{array}$ & 0 & $36 / 42(85.7 \%)$ & $42 / 42(100 \%)$ & $0.031^{*}$ \\
\hline $\begin{array}{l}\text { If there was no handwashing } \\
\text { facility on-site, would you } \\
\text { wash your hands with } \\
\text { alcohol-based hand } \\
\text { sanitizers or disinfected } \\
\text { wipes? (Yes, \%) }\end{array}$ & 0 & $30 / 42(71.4 \%)$ & $40 / 42(95.2 \%)$ & $0.006^{*}$ \\
\hline $\begin{array}{l}\text { Clean and disinfect house } \\
\text { regularly (Yes, \%) }\end{array}$ & 0 & $36 / 42(85.7 \%)$ & $31 / 42(73.8 \%)$ & 0.227 \\
\hline \multicolumn{5}{|l|}{$\begin{array}{l}\text { Frequency of household } \\
\text { cleaning and disinfection }\end{array}$} \\
\hline $\begin{array}{l}\text { No regular cleaning (Yes, } \\
\%)\end{array}$ & 2 & $6 / 40(15 \%)$ & $11 / 40(27.5 \%)$ & 0.227 \\
\hline Once a day (Yes, \%) & 2 & $7 / 40(17.5 \%)$ & $13 / 40(32.5 \%)$ & 0.146 \\
\hline $\begin{array}{l}\text { Once every } 2-3 \text { days } \\
\text { (Yes, } \%)\end{array}$ & 2 & $9 / 40(22.5 \%)$ & $10 / 40(25 \%)$ & 1.000 \\
\hline $\begin{array}{l}\text { Once a week or more } \\
\text { than a week (Yes, \%) }\end{array}$ & 2 & $18 / 40(45 \%)$ & $6 / 40(15 \%)$ & $0.012 *$ \\
\hline $\begin{array}{l}\text { Clean mobile phone } \\
\text { regularly (Yes, \%) }\end{array}$ & 1 & $18 / 41(43.9 \%)$ & $27 / 41(65.9 \%)$ & $0.012 *$ \\
\hline $\begin{array}{l}\text { Clean clothes and personal } \\
\text { belongings immediately } \\
\text { once get back home (Yes, }\end{array}$ & 0 & $15 / 42(35.7 \%)$ & $33 / 42(78.6 \%)$ & $<0.001 *$ \\
\hline
\end{tabular}




\begin{tabular}{|l|c|c|c|c|}
\hline$\%)$ & & & \\
\hline $\begin{array}{l}\text { Attend meal gatherings } \\
\text { (except for family members } \\
\text { cohabit with) regularly } \\
\text { (Yes, \%) }\end{array}$ & 0 & $25 / 42(59.5 \%)$ & $5 / 42(11.9 \%)$ & $<0.001^{*}$ \\
\hline $\begin{array}{l}\text { Number of meal gatherings } \\
\text { per month (Mean) }\end{array}$ & 0 & 2.78 & 0.14 & - \\
\hline $\begin{array}{l}\text { Number of meal gatherings } \\
\text { per month (Median) }\end{array}$ & 0 & 1 & 0 & $<0.001^{*}$ \\
\hline$*$ indicates P value $<0.05$ & & & \\
\hline
\end{tabular}

1 